\title{
Applying Salutogenesis in Schools
}

\author{
Bjarne Bruun Jensen, Wolfgang Dür, and Goof Buijs
}

\section{Introduction}

The chapter addresses the health of children and young people in the school setting with a special focus on experiences from Health Promoting Schools (HPS) and selected health promotion projects in schools. On the basis of brief definitions of the salutogenic orientation and the health promoting school model, comparisons will be conducted with regard to key concepts and principles of the two approaches to children's health.

A brief literature overview on the use of salutogenic concepts in relation to schools and health promoting schools is presented and discussed. One focus of interest is to compare the use of salutogenic concepts to the use of overlapping concepts, such as self-efficacy, resilience, and health literacy, and to briefly explore the distribution of the use of salutogenic concepts in the different European countries. Next, the main findings indicating links between schools and young people's sense of coherence are presented.

A number of projects using the HPS approach are described as examples of major interventions in the field, and the evidence on health and behavioural outcomes is summarised. The focus is on models and components with a clear overlap to the salutogenic orientation.

The main conclusion is that the salutogenic orientation has the potential to enlighten and stimulate HPS develop-

This chapter is a revision and update of work published in Mittelmark, M.B., Sagy, S., Eriksson, M., Bauer, G., Pelikan, J.M., Lindström, B., \& Espnes, G.A. (eds). (2017). The Handbook of Salutogenesis. Springer, Cham. DOI: https://doi.org/10.1007/978-3-319-04600-6.

B. B. Jensen $(\bowtie)$

Health Promotion Research, Steno Diabetes Center Copenhagen,

Gentofte, Denmark

e-mail: bjarne.bruun.jensen@ regionh.dk

W. Dür

Medical University of Vienna, Danube Private University and IMC

University of Applied Sciences Krems, Vienna, Austria

G. Buijs

UNESCO Chair Global Health \& Education, Paris, France ment and that intervention studies based on the HPS approach have the potential to enrich the intervention dimension of a salutogenic approach in schools. The chapter ends with recommendations for the further development of the salutogenic orientation viewed from a school health promotion perspective. Overall key conclusions from the chapter include the following:

- The key concepts of salutogenesis are not explicitly used in the field of HPS, although several HPS concepts are closely related to the salutogenic orientation, such as empowerment, action competence, democracy, equity, participation, and the multidimensional notion of health.

- HPS and health promotion projects in schools will benefit from a more coherent and systematic theoretical and philosophical basis-and salutogenesis has the potential to fill out parts of this gap.

- Findings and observations from the field of school health promotion have the potential to improve and strengthen the intervention and practice base of salutogenesis in relation to the school setting.

\section{Salutogenesis and the Sense of Coherence}

In the following, we briefly present how salutogenesis and the salutogenic orientation might be used as an umbrella and as a philosophical underpinning of the HPS movement. First, we introduce our understanding of the salutogenic orientation within the context of health promoting schools. Next, we present the relevant key concepts for HPS, including the whole school approach to health, a multidimensional health concept, and participation and democracy as basic principles for a health promoting school.

In this chapter, we understand salutogenesis as an overarching theory, leading to a salutogenic orientation. Key to this is the concept sense of coherence, which is an orientation to life, helping the person to live and cope with life and facilitating the development of the person towards health. 
According to Antonovsky $(1987,1996)$, the salutogenic orientation can be described by the following three components:

1. To focus on all people in the system (and not only on people at risk).

2. To address and promote salutary factors (and not only remove risks).

3. To focus on the whole person (and not only on a specific disease).

Further, Antonovsky (1987) defined the core notion of the sense of coherence by the following three dimensions:

1. Meaningfulness: a belief that things in life are interesting, motivating, and a source of satisfaction (motivational).

2. Comprehensibility: a belief that the challenge is understood and that you can understand events in your life (cognitive).

3. Manageability: a belief that resources to act are available and that things are manageable and within your control (behavioural).

Finally, these components and dimensions are united in the concept of generalised resistance resources, which are all the resources that help a person (or a collective) to avoid or tackle a range of psychosocial stressors.

During the presentation of the scope and context of HPS, we draw on-and refer to- these key concepts and dimensions of salutogenesis when relevant.

\section{A Health Promoting School}

In this section, we use the overall definition of a Health Promoting School (HPS) used in the recent Cochrane review (Langford et al., 2014). According to this review, HPS embraces the following three areas:

1. Formal health curriculum: Health education topics are given specific time allocation within the formal school curriculum to help students develop the knowledge, attitudes, skills, and competencies needed for healthy choices.

2. Ethos and environment of the school: Health and wellbeing of students and staff are promoted through the hidden or informal curriculum, which encompasses the values and attitudes promoted within the school and the physical and social environment and setting of the school.

3. Engagement with families or communities or both: Schools seek to engage with families, outside agencies, and the broader community to recognise the importance of these other spheres of influence on children's attitudes and behaviours.

In addition to this, the Cochrane review also presents a so-called logic model—or a programme theory (Pawson \& Tilley, 1997) - to illustrate the mechanisms for how an HPS might influence health and educational outcomes (Fig. 29.1).

Health promotion in a school setting is a broad and innovative concept rooted in the Ottawa Charter (WHO, 1986). The principles and action areas in the Ottawa Charter, such as building healthy policy, creating supportive environments, and empowerment of individuals, relate clearly to the salutogenic orientation (Eriksson \& Lindström, 2008).

Based on these principles, there is a clear distinction between HPS and the more traditional health education in schools, mainly focused on presenting health knowledge (often exclusively related to risk factors) to pupils. An HPS is based on a so-called Whole School Approach where health education and teaching are combined with school policies, the physical and social school environment, and the surrounding community, including parents and health services. Furthermore, the focus is on promoting health rather than preventing a specific disease.

This approach combines a commitment to improving the health and well-being of children and young people and to making schools a better place to learn and work. Furthermore, it also encompasses the health and well-being of school staff. Therefore, health promotion in schools needs to be linked to the core task of a school (which is education) and to its inherent values, such as inclusion, democracy, participation and influence, critical health literacy, and action competence in relation to health.

An HPS approach demands an intersectoral strategy. The Odense Statement, resulting from the fourth European conference on health promoting schools, calls for strengthening links between the education and health sector and all stakeholders (https://www.schoolsforhealth.org/resources/conference-statements). Furthermore, it focuses on taking a lead in school development and school improvement through a health promoting school approach.

Similarly, the Global School Health Statement from the first Global School Health Symposium in Pattaya in 2013 calls for a dialogue to better understand education, and more specifically, that the health sector seeks integration within the educational system (http://www.wholechildeducation. org/about/globalschoolhealthstatement). The statement also recommends focusing on the growth and development of the whole child rather than directing attention and resources only towards specific diseases or behaviours. Disease intervention is, of course, important but needs to be embedded in overall health and development, or salutogenic framework, refocusing attention on a setting-based approach. 


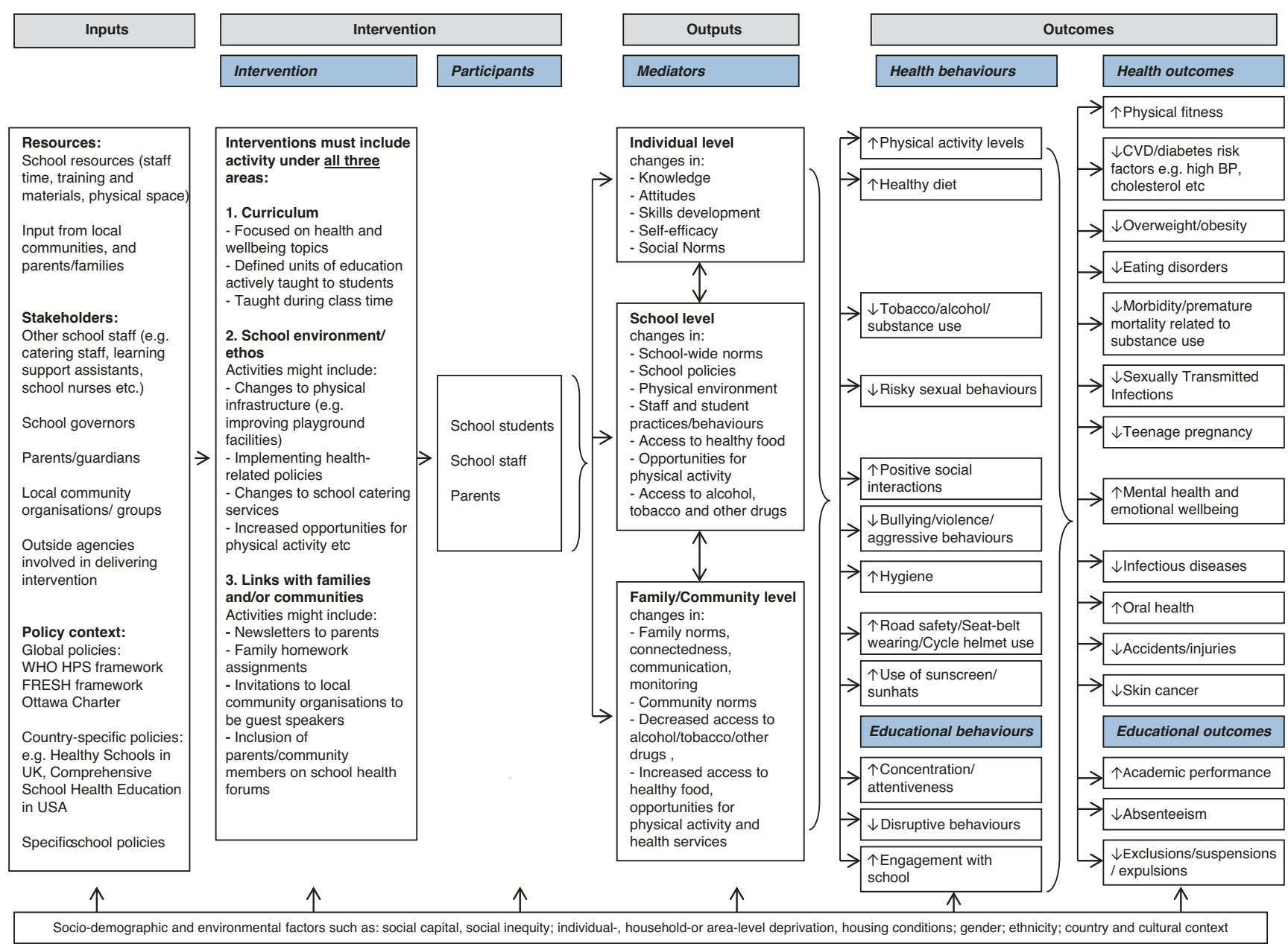

Fig. 29.1 Logic model for the impact of HPS on health and learning outcomes (Reprinted with permission from Langford et al., (2014). Copyright (C) 2014 The Cochrane Collaboration. Published by John Wiley \& Sons, Ltd. All Rights Reserved)

The latest statement from the fifth HPS conference in Moscow in 2019 mentions the notion of salutogenesis explicitly:

\footnotetext{
'We welcome new and established concepts and approaches within school-based health promotion, such as health literacy, salutogenesis, action competence, and life skills, which should complement each other and be integrated in the holistic framework of the Health Promoting School approach'. (Dadaczynski et al., 2019)
}

As a new dimension, the statement recommends using a resource-oriented approach when addressing Noncommunicable Diseases (NCDs), namely that.

'... a resource-oriented intervention approach (as described in the SHE [Schools for Health in Europe] values and pillars) be taken to tackle NCDs rather than a traditional top-down and disease-oriented approach, which normally dominates interventions related to risk factors ... and ... young people be viewed as part of the solution and not only as part of the problem of NCDs - we need to work with young people as powerful agents of healthy change and not as victims and recipients of risk factors'.

Finally, the Health 2020 policy adopted in 2012 by all WHO European member states declares that integrative policies should be developed that engage all sectors in our societies in addressing the determinants of health. Health 2020 also puts a strong emphasis on reducing health inequalities. Children from poorer backgrounds are more likely to experience poor parenting, receive inadequate support in schools and health services, live in hazardous environments, and live shorter and less healthy lives as adults. Education policies and schools can help address these inequalities. The WHO EURO H2020 sectoral brief on education and early development (2014) states very clearly how education can make a difference in health. Creating better synergy between health and education sectors implies improving education outcomes to create healthy adults. 
Based on the concepts and models presented, it is evident that an HPS approach is closely linked to salutogenesis and its core dimensions. Focus is on the whole school community, a resource-oriented approach, the whole child, and improving children's competencies and skills to act to promote their health. The values and principles will be further discussed under the description of the European Health Promoting School initiative later in this chapter, making the links to the salutogenic orientation even more explicit.

\section{Salutogenesis and Schools}

This section summarises the literature on salutogenesis and schools-independent of health promotion interventions. In the first part, we present a brief overview of how frequent the salutogenic concepts have been used in the literature related to schools and health promoting schools. Among other things, we compare it with overlapping concepts (such as self-efficacy, resilience, etc.), and we also explore the distribution of salutogenic concepts in the different European countries and various disciplines. Further, we introduce the main findings indicating links between schools and young people's sense of coherence. Although there is only limited research exploring the links between salutogenesis and applying HPS approaches, we present and discuss the findings from these studies.

Lindström and Eriksson (2010) define salutogenesis as an umbrella concept, underneath which concepts and theories gather that contribute to our understanding of how health is maintained, strengthened, or set at risk. Salutogenesis, therefore, does not only relate to the explicit measurement and the application of sense of coherence but is a much broader framework, touching on concepts like empowerment, selfefficacy, quality of life, resilience, well-being, action competence, and several other concepts. While it is universally agreed that all those constructs relate to salutogenic dimensions and make valuable contributions in describing, explaining, analysing, and promoting health, some researchers also claim that Antonovsky's salutogenic theory is still the best explored and with the broadest evidence base (e.g. Lindström, 2010).

In an often-cited quote, Antonovsky argues that the sense of coherence would build up from experiences in childhood and adolescence and would first gain stability in early adulthood or as he puts it:

The adolescent, at the very best, can only have gained a tentative strong sense of coherence, which may be useful for a short-range prediction about coping with stressors and health status (Antonovsky, 1987, p. 107).

The notion of sense of coherence resulting from the developmental process during childhood and adolescence indi- cates that the concept is seen as an outcome of individual life experiences, learning processes, and environmental influences and not primarily as a resource and determinant of positive health. Any developmental stage of sense of coherence that a child has reached can also be seen as a resource for coping with the challenges that the child is facing at this stage. But it seems that the time factor in developmental processes is not trivial since both-the child and the childspecific environment-change simultaneously over 20 years and more. Therefore, the level of sense of coherence reached at any time may inevitably lag behind the levels of experienced challenges, as long as the developmental process has not come to a certain point of preliminary optimum.

The mechanisms described in salutogenesis to translate growing challenges into a growing sense of coherence, although with a time lag and only under the condition of coping success, are the generalised action and resistance resources. As they grow and convey positive coping experiences, children develop a general feeling of comprehensibility and manageability of demands and a sense of meaningfulness regarding life and the mastering of challenges. Seen from this perspective, childhood and adolescence are seen as crucial life phases, crucial for developing the personal sense of coherence optimum and the individual health biography.

This is the point where HPS could re-orient services. If sense of coherence is the mental fundament that supports all other life skills, then HPS and education as a whole should primarily provide opportunities for acquiring generalised resistance resources. This is slightly different from the current orientation towards well-being that many HPS schools have declared their guiding philosophy.

It must be mentioned that there is still some ambiguity regarding the stability of sense of coherence over time in young as well as among adult populations. Currently, there are only a few longitudinal studies that indicate such stability. However, the methodologies and results of these studies are subject to several limitations, such as selecting target populations, the definition of follow-up periods, the use of different sense of coherence-questionnaires, and the fact that most of these studies have been conducted in Scandinavian countries.

To get an idea about the popularity of salutogenesis in the literature on schools and HPS, we conducted a brief literature search in the Web of Science database (in October 2019), looking for studies that prominently focus on the sense of coherence and salutogenesis. For comparison, we selected four additional popular concepts from the salutogenic umbrella (Lindström \& Eriksson, 2010): well-being, selfefficacy, quality of life, and health literacy.

The search was conducted as a simple title search of all the terms mentioned above (and commonly known synonyms) combined with the following keywords: school, stu- 
Number of journal articles including health concepts together with school, student and education in titles

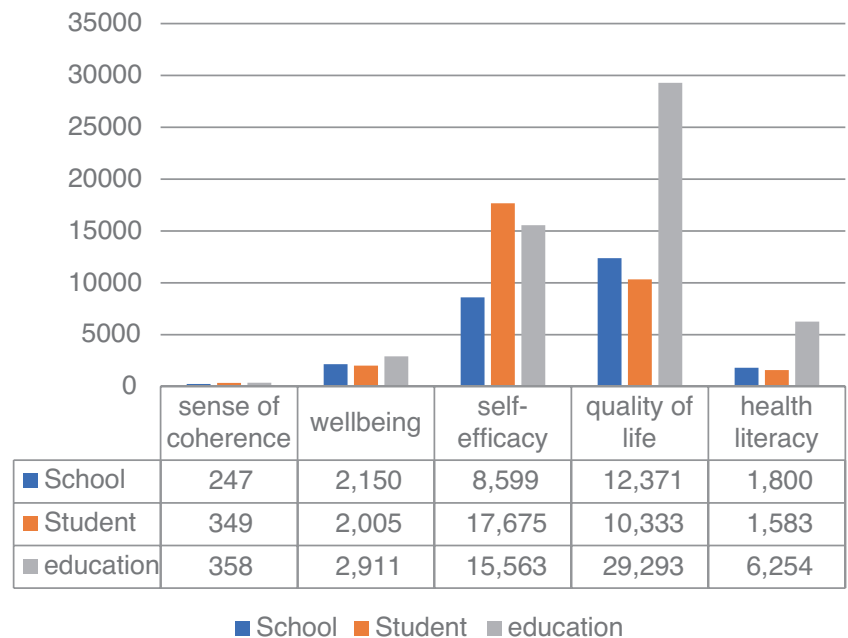

Fig. 29.2 Number of studies that use sense of coherence, well-being, self-efficacy, quality of life, and health literacy in a school setting (school, student, and education). Studies are counted for each keyword

dent, and education, which operationalised the relevant context for our purpose. Studies with more than one keyword in the title were counted for each; hence, the number of studies cannot be added. We do not claim completeness for our research strategy. Still, we argue that the restriction to the title is a valid indicator for the overall use of the concepts in the specific study and, therefore, in the relevant international literature.

From Fig. 29.2, it can be concluded that sense of coherence is still rarely used in studies related to the school setting. Only 954 publications were identified with sense of coherence in the title, but 7.066 for well-being, 41.837 for self-efficacy, 51.997 for quality of life, and 9.637 for health literacy.

\section{Relations between School, Sense of Coherence, and Young People's Health}

In this section, we summarise the limited amount of studies that have analysed relations between school, sense of coherence, and health among children and adolescents. Some studies treat sense of coherence as a determinant (an independent variable), whereas other studies look at sense of coherence as an outcome of, for example, educational interventions (dependent variable).

Most studies that investigate the relationship between adolescence and sense of coherence do not look at specific life experiences of children and adolescents, be it in the family, in the school, or leisure activities. They use the gener- alised resistance resources in the phase of adolescence as causal determinants for the development of the sense of coherence in adulthood. Antonovsky $(1987,1996)$ defines generalised resistance resources as the biological, material, and psychosocial conditions of an individual in its inner and outer environment, for example, the health status, cognitive abilities, level of parental support, parents' education level, and parental socioeconomic status.

Feldt et al. (2005) investigated child-centred parenting, parental socioeconomic status, school success in adolescence, and career orientation in adulthood as determinants of adult SOC. They gathered data at ages 14, 27, 36, and 42. They found that only parental child-centredness and career orientation have a direct, as well as an indirect (via education and stability of career line), relationship with adult sense of coherence (Feldt et al., 2005, p. 305). As for the stability of sense of coherence in adulthood, Hakanen, Feldt, and Leskinen (2007, p. 612) found that stability after age 30 depended strongly on its level at younger ages. Higher initial levels are more likely to be stable, and the early level of sense of coherence is influenced by the level of generalised resistance resources in adolescence.

Both studies demonstrate that adolescence and the family as bundles of generalised resistance resources are highly relevant for the development of the sense of coherence, and this seems to be true even more for early adolescence up to age 15 than for later phases. Hokinen et al. (2008) investigated the stability of sense of coherence during adolescence. They found that the change in the sense of coherence between the age of 15 and 18 years was not significant (Hokinen et al., 2008, p. 89). This suggests that the development of the sense of coherence is stronger before the age of 15 than after, and also-contrary to an assumption of the theory-that the stability of sense of coherence did not depend on its initial level.

García-Moya et al. (2013) analysed data from the international Health Behaviour among School-aged Children (HBSC), a cross-national questionnaire survey conducted every four years in up to 44 countries and regions across Europe and North America (Currie et al., 2010). They observed that a supportive school environment (classmate and teacher support) was related to the level of students' SOC. School-related stress and sense of coherence also showed a strong correlation, but the direction stayed unclear since the study used self-report data. By relating to the model of Salutogenesis, García-Moya et al. (2013) solved the problem in two directions: They interpret sense of coherence as an outcome of a supportive school environment and as a determinant in relation to the experience of stress. They concluded that:

\footnotetext{
'a supportive school environment also tended to reduce the likelihood of perceiving school demands as stressful, not only by reinforcing sense of coherence, but also through a direct effect on the perception of school-related stress'.
} 
In this view, sense of coherence is seen as an internal mediator of internal effects from external environmental factors (negative ones like demands and positive ones like support) by amplifying the positives. Still, sense of coherence (in particular the components comprehensibility and manageability) and the concept of adaptation in stress theory are so close that their mutual relation and direction of causes are difficult to tease apart based on self-reported data.

Also based on HBSC-data, Torsheim et al. (2001) found a substantial increase in perceived stress between the grades 5 and 9, but only a slight increase in sense of coherence at the same ages. They also use sense of coherence as a determinant. They argue that, in the course of the school career, the academic demands increase faster and more threatening implying that adolescents are not able to fully develop an adolescent sense of coherence at the same pace. The experience of stress might, therefore, be viewed as a result of a time lag in the development of SOC. In other words, according to Torsheim et al. (2001), the development of sense of coherence cannot keep up with the various challenges and demands an adolescent is facing in the course of growing up.

To summarise, studies with a developmental psychology approach tend to use sense of coherence as an outcome of developmental processes, but predominantly look into the family as the primarily relevant setting for children and adolescents. Studies in the area of the school setting, on the other hand, tend to use sense of coherence as a determinant and therefore fail to investigate the school as a highly relevant social system for the development of a strong, protective SOC.

Therefore, the scarce research results do not allow for a conclusion of the role of sense of coherence in childhood and adolescence. This is where we see the most urgent need for research: intervention studies in the school setting that can clarify pathways leading to high or low sense of coherence levels and that provide indications and guidelines for changes in the school setting to optimise the development of students' SOC. The national and international networks of HPS provide perfect platforms for natural experiments for this purpose.

\section{Health Promoting Schools and a Salutogenic Orientation}

As stated earlier, there are many similarities between the HPS approach and the salutogenic orientation. In this section, a few major interventions related to the HPS approach are presented and discussed with a specific focus on the salutogenic orientation.

The European Network of Health Promoting Schools, now called the Schools for Health in Europe (SHE) network, is structured around its 45 member states in the European region (http://www.schools-for-health.eu). In 2013, a survey was conducted among the national coordinators of the SHE network in Europe to gain an overview of current health promoting school policies in the then 43 member countries. Nearly two in three countries $(62 \%)$ have a formal health promoting school policy, in most cases as part of their education policies, followed by inclusion in their public health policies, or a combination of education and health policies.

Based on the 2013 survey, a minimum of 34,000 schools in the European region is registered as health promoting schools. These include preschools, primary schools, secondary schools, and other school types. It must be kept in mind that the diversity of the different education systems among countries in the European region is huge. There are differences in starting age and programme duration, different models for compulsory education, and educational standards and goals. Also, each country has its standards and indicators for being a health promoting school. Despite this diversity, all SHE member countries share principles and core values concerning health promoting schools.

SHE has had a strong link to research, which among others has led to the development of new concepts and models of health promotion in schools-concepts, which are closely related to the salutogenic orientation.

In the SHE network (2013), a health promoting school is defined as 'a school that implements a structured and systematic plan for the health and well-being of all pupils and of teaching and non-teaching staff'. This is characterised as a whole school approach which consists of the following six components:

- Healthy school policies are clearly defined documents or in accepted practice that is designed to promote health and well-being.

- School physical environment includes the buildings, grounds, and school surroundings.

- School social environment relates to the quality of the relationships among and between school community members.

- Individual health skills and action competencies can be promoted through the curriculum such as through school health education and through activities that develop knowledge and skills which enables students to build competencies and take action related to health, wellbeing, and educational attainment.

- Community links between the school and the students' families and the school and key groups/individuals in the surrounding community.

- Health services are the local and regional school health services or school-linked services that are responsible for the students' health care and health promotion by providing direct student services.

The whole school approach used in the SHE network, therefore, rests on several core values (equity, sustainability, 
inclusion, empowerment, action competence, and democracy) and a set of pillars (whole school approach to health, participation, school quality, evidence base, the involvement of schools and communities).

\section{The Whole School, Whole Community, Whole Child Model}

Another recent example of an intervention and a conceptual development in this area is the 'Whole School, Whole Community, Whole Child' model (http://www.ascd.org/programs/learning-and-health/wscc-model.aspx). In the late 1980s, the coordinated school health (CSH) model was introduced by the American CDC (Centers for Disease Control and Prevention). This model demonstrated how a comprehensive approach to school health could be shaped. The CSH model was widely accepted and supported by many health and education organisations. But it can also be argued that educators viewed the model as primarily a health initiative focusing on health outcomes only. Therefore, acceptance across the education sector at the school level was somehow limited.

In 2014, Association for Supervision and Curriculum Development (ASCD), a leading worldwide education development organisation together with CDC (n.d.), developed a new model for school health that combines the CSH model with the whole child initiative from ASCD to strengthen a collaborative approach to learning and health. Their 'Whole School, Whole Community, Whole Child' model (Fig. 29.3) demonstrates how education and health together support the development of children-cognitive, physical, social, and emotional. It is described as an ecological model, integrating the current whole-school approach with a whole-child approach to education (http://www.ascd.org/whole-child. aspx) and the influences of the local community.

\section{Shape Up as a Salutogenic Health Promotion Project}

Another intervention founded on the principles of pupil participation and a whole school approach is the EU-funded SHAPE UP project, focusing on overweight and obesity in children and young people (Simovska \& Jensen, 2010). Although the fundamental premise of Shape Up was that healthier eating and regular physical activity are keys to preventing childhood obesity and promoting the health and well-being of children and young people, the project was built on a salutogenic approach.

The starting point was that promoting healthy diet and physical activity is influenced in more efficient and sustainable ways by addressing their determinants on a school, fam- ily, community, and broader societal level, rather than solely on an individual behaviour level. Furthermore, health was framed in the project as a positive concept: play and dance instead of physical activity, food, meals, and eating instead of nutrition, etc. Therefore, a key to Shape Up was the involvement of children and young people themselves through their schools in investigating the social determinants of health and formulating positive and visionary proposals for action to address them.

Within the SHAPE UP project, the IVAC approachInvestigation, Vision, Action and Change-(Jensen, 1997, 2004) was used as a guiding framework to support children in taking concrete actions to improve the determinants behind their health. In practice, this typically meant improving the quality of food on offer in school, enhancing opportunities for physical activity in the school and community settings, and increasing parents' understanding of health issues. Because of the relationship between schools and the local promoting group, young people could see their ideas turned into action, and the individual development promoted by the programme could be supported by changes in policy and infrastructure at a local level.

The Shape Up project did not focus on tackling inequality per se. Still, the project demonstrates that children and young people can initiate processes that improve determinants in their local environment and thereby promote the health of all children (including vulnerable young people).

In another project, the IVAC approach used in the SHAPE UP project was proven effective in an area in Northern Spain (Llargues et al., 2011). The outcomes that were successfully achieved included children's BMI, showing that a participatory and action-oriented approach, building on a positive health concept, also might lead to successful preventive outcomes.

\section{Relations Between HPS and Young People's Health and Learning}

When children grow up, their family and homes are key determinants of their health and well-being. When they enter the education system, their schools, peers, and communities in which they live also become important in determining their health. So education is another key determinant to their health. Children starting their education in early life, such as preschool or kindergarten, are more likely to do well at school, get better-paid employment, and have better health in adulthood. Education is a key tool to help reducing inequality in income in our globalised economy, which is also recognised in the recent publication by economist Thomas Piketty on capital in the twenty-first century.

The 2013 factsheet of the SHE network provides an overview of the evidence of school health promotion (2013). 
Fig. 29.3 The Whole School, Whole Community, Whole Child (WSCC) model, developed by CDC and ASCD (CDC, n.d.)

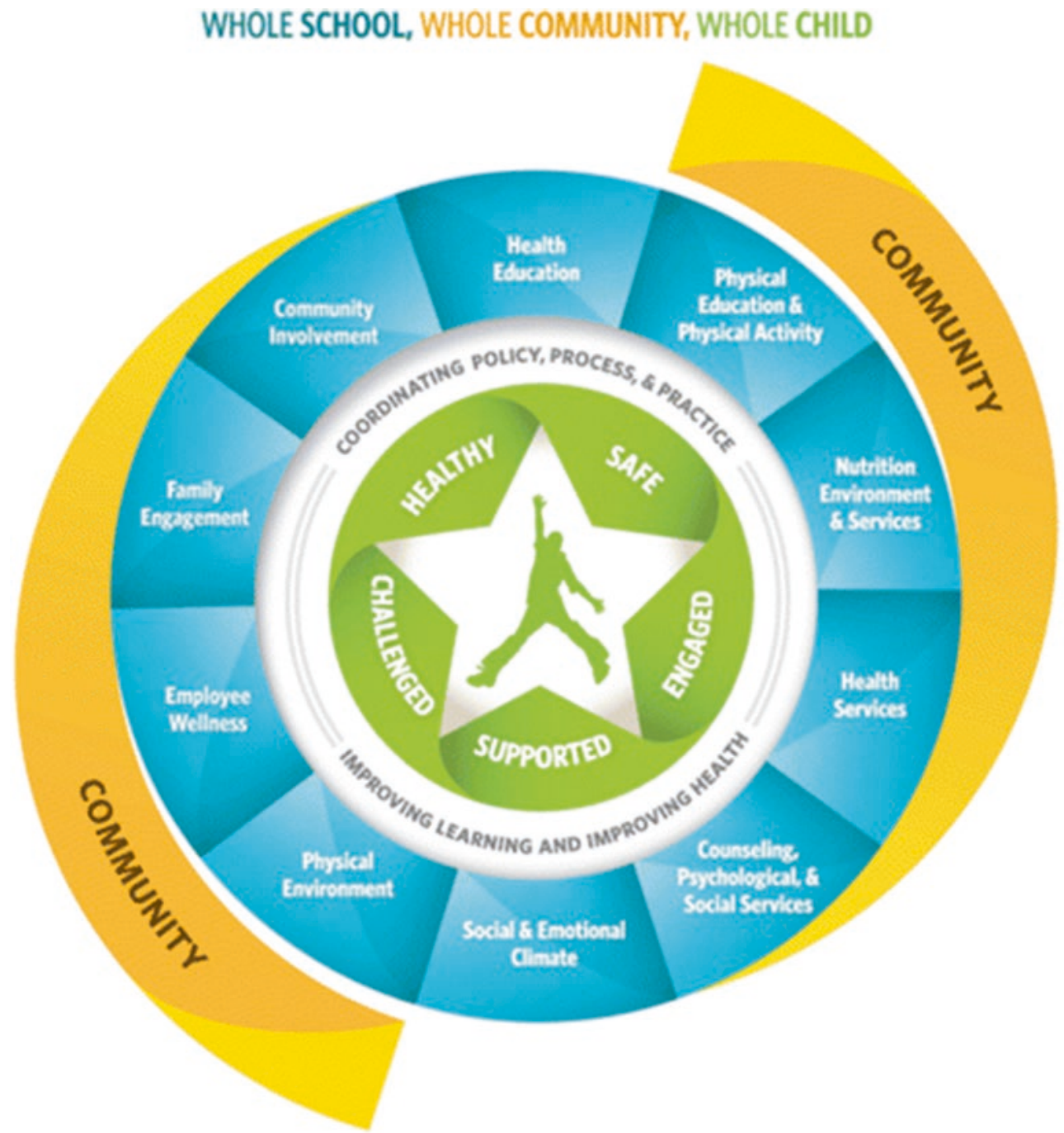

Most of the HPS evidence traditionally comes from health topic research (on healthy eating, physical activity, and tobacco use), rather than from research looking at wholeschool approaches or looking at initiatives focusing on health more holistically. The overall conclusion from topic-based research is that programmes that can be classified as a health promoting school or whole-school approach deliver most evidence on improving health behaviours. This is especially true for mental health programmes in schools. Successful mental health initiatives are well designed and based on theory and practice, have links between school, community and parents, and school environment, and focus on relationships among students, teachers, and parents (2013).

Results are varied and demonstrate improvements in achievement tests and social and emotional skills and decreases in classroom misbehaviour, anxiety, and depression. There are also demonstrated benefits concerning the reduction of aggressive behaviour, school drop-out rates and building a sense of community in the school. Similar positive links have been shown on other topics with a whole school approach, specifically in the area of promoting healthy eating and physical activity. It is stated that mental health should be a feature of all school health promotion initiatives.

The 2014 Cochrane review on the WHO health promoting school framework, based on cluster randomised control trials, concludes that there is some evidence that school-based intervention building on an HPS framework is effective at improving several health outcomes in children and young people. It found evidence of significant, positive effects on body mass index (BMI), physical activity, physical fitness, fruit and vegetable intake, tobacco use, and being bullied. It also stated that it had not been demonstrated that the HPS framework could have an impact on other outcomes, such as mental health or attainment. The most important limitation of this review is that the many studies that are not designed as randomised control trials were not included.

Other reviews, such as the Stewart-Brown, 2006 review, commissioned by WHO EURO, use a wider lens to evaluate what worked well and what are prominent features of a whole school approach (Stewart-Brown, 2006). The review 
was a systematic review of robust, systematic reviews of the impact of school health promotion initiatives on some aspects of health or well-being. It did, therefore, not only include randomised controlled trials. It concludes that the school health promotion programmes that were effective in changing young people's health or health-related behaviour were more likely to be complex, multifactorial and involve activity in more than one domain (curriculum, school environment, and community).

A paper from the International Union for Health Promotion and Education (IUHPE) shows that activities in schools on improving health and well-being are a product of interaction between school management and educational practices (St Leger et al., 2010). A supportive educational climate will motivate children and young people to be effective learners and at the same time, lead to better health and well-being.

It can also be concluded that interventions that take a whole school approach and target all students have a higher impact, everything else being equal. Furthermore, a positive health concept-as explicitly spelt out in SHE and Shape Up-improves the likelihood for improving students' ownership and therefore, also for facilitating sustainable healthy changes.

\section{Discussion and Conclusions}

One of the obvious observations is that the salutogenic orientation, including key concepts such as sense of coherence, is rarely used explicitly in the field of school health promotion and HPS. Nevertheless, the different HPS interventions presented in this chapter demonstrate clear and obvious overlaps to the salutogenic orientation. Therefore, we only partly agree with Sagy that only a small number of holistic programmes have been developed all over the world, which are salutogenic oriented (Sagy, 2014). In other words, the HPS movement includes many different examples of interventions which could be labelled salutogenic, although they are described by terms from other scientific directions and areas.

Within the SHE approach and related models, there is a clear focus on all people in the school system, and the aims are to improve salutary factors and not only remove risks. Both characteristics are well and explicitly reflected in the 'whole school approach' that is underpinning SHE, WSCC, the SHAPE UP project, etc.

Furthermore, all projects described in this section are dealing with the whole child instead of only addressing disease and risks dimensions, in other words, the focus is on a salutogenic (and not a pathogenic) approach.

Key concepts related to the notion of health are wellbeing, quality of life, being in control, competence to take action, play and dance (and not physical activity) as well as food, meals, and school canteens (and not nutrition pyramids and fatty acids). This positive way of phrasing health is a precondition for reaching another key principle in the HPS approach: students' active participation and involvement which creates internationalisation and ownership and therefore also the potentials for sustainable healthy change. The principle of participation is, therefore, also consistent with Antonovsky's underlining of participation in socially valued decision-making as a prerequisite for developing a strong sense of coherence (Antonovsky, 1996, p. 15).

We, therefore, agree with Morgan (2014) that we need to strengthen the focus of involving individuals and local communities in the salutogenic practice as the more health programmes are developed with and by local people the more likely they are to be successful and sustainable (Morgan, 2014, p. 4).

Finally, there are also substantial overlaps and links between HPS concepts like empowerment, action competence, and self-efficacy and the salutogenic concepts sense of coherence and Generalised Resistance Resources. The metaphor suggested by Antonovsky (1996) and further developed by Eriksson and Lindström (2008) on the river of health is a good illustration for visualising overlaps between these concepts. Where curative medicine is devoted to helping people who are drowning and preventive medicine is helping people not to fall into the river, the salutogenic approach is focusing on enabling people to swim. Empowerment, action competence, and similar concepts from the HPS area do have the same potential and roles: to enable people to swim-as single individuals and together.

There is a need for more research which uses a wide range of methods. Also, more systems research, which attempts to assess the synergic interactions which can occur the complex reality of a school, is needed. Good practice is also part of the evidence, and the SHE network strongly advocates disseminating good practice studies results. The goal of embedding good practice in education systems is not yet accomplished. The potential of schools in improving health and reducing health inequalities needs to be better utilised and underpinned with research.

From the interventions and cases presented, it is clear that there is a substantial link between HPS and whole-school approaches and the salutogenic orientation. The emerging evidence for the effects of such approaches could be used to anchor and document the effects of a salutogenic approach in schools. One important focus area for future research could be to clarify the role of sense of coherence in an HPS, which could perhaps be viewed as an intermediary and mediating factor between participatory whole-school approaches and behavioural and health outcomes.

What the HPS development is currently lacking is a clear and commonly agreed overall theory, which is where the salutogenic area could help to embed and anchor school 
health promotion and HPS. On this basis, we conclude that salutogenesis can contribute with a theoretical fundament for HPS and related approaches.

On the other hand, the intervention models and the appearing evidence of the effectiveness of an HPS approach described in this chapter can be used to strengthen the actionorientation and intervention dimension of the salutogenic theory. In other words, the HPS might help to operationalise and describe the salutary factors in the salutogenic theory, which can be viewed as the current weakest link in the salutogenic orientation.

\section{Future Challenges}

There is a need to develop, test, and implement intervention studies in the school setting that can clarify pathways leading to high or low sense of coherence levels and that provide indications and guidelines for changes in the school setting to optimise the development of students' SOC. The national and international networks of HPS provide perfect platforms for natural experiments for this purpose.

The role of sense of coherence as a possible mediator between a participatory and action-oriented HPS and behavioural and health outcomes need to be explored, mapped out, and clarified. In this regard, the sense of coherence can be viewed as a determinant as well as an outcome in the HPSsetting and as a dependent as well as an independent variable in future research.

Relations between the sense of coherence and typical HPS concepts (e.g. empowerment, health literacy, selfefficacy, and action competence) should be explored and mapped out. The focus should be on theoretical underpinnings, measurements, relations to health outcomes, and internal synergies.

Salutogenic approaches and models need to strengthen the community or collective dimensions since no one is in control of her/his health as a single, isolated individual. HPS models and concepts like empowerment and action competence do have the potentials to emphasise and strengthen key elements in the intervention part of the salutogenic orientation such as connectedness, collective action, and social capital as key social-level generalised resistance resources.

\section{References}

Antonovsky, A. (1987). Unraveling the mystery of health. How people manage stress and stay well. Jossey-Bass.

Antonovsky, A. (1996). The salutogenic model as a theory to guide health promotion. Health Promotion International, 11(1), 11-18.

Centers for Disease Control and Prevention (CDC). (n.d.). The whole school, whole community, whole child (WSCC) model. https:// www.cdc.gov/healthyyouth/wscc/model.htm. Accessed 1 Mar 2021.

Currie, C., Griebler, R., Inchley, J., Theunissen, A., Molcho, M., Samdal, O., et al. (Eds.). (2010). Health Behaviour in School-Aged Children (HBSC) study protocol: Background, methodology and mandatory items for the 2009/2010 survey. CAHRU.

Dadaczynski, K., Jensen, B. B., Grieg Viig, N., Sormunen, M., von Seelen, J., Kuchma, V., Vilaça, M. T., \& on behalf of the conference participants. (2019). Health, Well-being and education: Building a sustainable future. The Moscow Statement on Health Promoting Schools. https://www.schoolsforhealth.org/resources/conferencestatements/moscowstatement. Accessed 1 Mar 2021

Eriksson, M., \& Lindström, B. (2008). A salutogenic interpretation of the Ottawa charter. Health Promotion International, 23(2), 190-199.

Feldt, T., Kokko, K., Kinnunen, U., \& Pulkkinen, L. (2005). The role of family background, school success, and career orientation in the development of sense of coherence. European Psychologist, 10(4), 298-308.

García-Moya, I., Rivera, F., \& Moreno, C. (2013). School context and health in adolescence: The role of sense of coherence. Scandinavian Journal of Psychology, 54(3), 243-249.

Hakanen, J. J., Feldt, T., \& Leskinen, E. (2007). Change and stability of sense of coherence in adulthood: Longitudinal evidence from the health child study. Journal of Research in Personality, 41, 602-617.

Hokinen, P.-L., Suominen, S., Helenius, H., Aromaa, M., Rautava, P., Sounrander, A., et al. (2008). Stability of the sense of coherence in adolescence. International Journal of Adolescent Medicine and Health, 20(1), 85-91.

Jensen, B. B. (1997). A case of two paradigms within health education. Health Education Research, 12(4), 419-428.

Jensen, B. B. (2004). Environmental and health education viewed from an action perspective-A case from Denmark. Journal of Curriculum Studies, 36(4), 405-425.

Langford, R., Bonell, C. P., Jones, H. E., Pouliou, T., Murphy, S. M., Waters, E., et al. (2014). The WHO health promoting school framework for improving the health and Well-being of students and their academic achievement. Cochrane Database of Systematic Reviews, 4, CD008958. https://doi.org/10.1002/14651858.cd008958.pub2

Lindström, B. (2010). Salutogenesis - an introduction. Retrieved December 01, 2014, from htttp://www.ndphs.org/?download,4670 ,SALUTOGEN+ESIS+and+NCDs.pdf

Lindström, B., \& Eriksson, M. (2010). The Hitchhiker's guide to Salutogenesis. Salutogenic pathways to health promotion. Folkhälsan Research Centre.

Llargues, E., Franco, R., Recasens, A., Nadal, A., Vila, M., Pérez, M. J., et al. (2011). Assessment of a school-based intervention in eating habits and physical activity in school children: The AVall study. Journal of Epidemiology \& Community Health, 65, 896-901.

Morgan, A. (2014). Revitalising the asset model: A clarification of ideas and terms. Global Health Promotion, 21(2), 3-6.

Pawson, R., \& Tilley, N. (1997). Realistic evaluation. Sage.

Sagy, S. (2014). Preventing drug abuse among children and adolescents: Where does the salutogenic approach direct us? Health, 6, 541-548.

SHE (Schools for Health in Europe). (2013). SHE factsheet 2: School health promotion-Evidence for effective action. CBO. Retrieved from https://www.schoolsforhealth.org/sites/default/files/editor/ fact-sheets/she-factsheet-2-school-health-promotion-evidence.pdf .

Simovska, V., \& Jensen, B. B. (2010). Shape Up Europe. A school community approach to influencing the determinants of childhood overweight and obesity. Lessons learnt. PAU Education. Retrieved from http://paueducation.com/projects/shape-up and http://www.shapeupeurope.net/files/media/media430.pdf.

St Leger, L., Young, I., \& Blanchard, C. (2010). Health promotion in schools: From evidence to action. International Union for health promotion and Education. Retrieved from http://www.iuhpe.org/ index.html?page=516\&lang=en\#sh_advevid. 
Stewart-Brown, S. (2006). What is the evidence on school health promotion in improving health or preventing disease, and specifically, what is the effectiveness of the health promoting schools approach? WHO Regional Office for Europe.

Torsheim, T., Aaroe, L. E., \& Wold, B. (2001). Sense of coherence and school-related stress as predictors of subjective health complaints in early adolescence: Interactive, indirect or direct relationships? Social Science and Medicine, 53(5), 603-614.

World Health Organization (WHO). (1986). Ottawa charter for health promotion. WHO.

Open Access This chapter is licensed under the terms of the Creative Commons Attribution 4.0 International License (http://creativecommons. $\mathrm{org} / \mathrm{licenses} / \mathrm{by} / 4.0 /)$, which permits use, sharing, adaptation, distribution and reproduction in any medium or format, as long as you give appropriate credit to the original author(s) and the source, provide a link to the Creative Commons license and indicate if changes were made.

The images or other third party material in this chapter are included in the chapter's Creative Commons license, unless indicated otherwise in a credit line to the material. If material is not included in the chapter's Creative Commons license and your intended use is not permitted by statutory regulation or exceeds the permitted use, you will need to obtain permission directly from the copyright holder. 